\title{
CONSTRUÇÃO E COMUNICAÇÃO DE UMA MARCA TERRITORIAL: O CASO DO MUNICÍPIO DE VIANA DO CASTELO
}

\author{
GORETE MARQUES \\ INSTITUTO POLITÉCNICO DE LEIRIA \\ LEIRIA, PORTUGAL \\ GORETE.MARQUES@IPLEIRIA.PT
}

ROSA SOBREIRA INSTITUTO POLITÉCNICO DE COIMBRA COIMBRA, PORTUGAL RSOBREIRA@ESEC.PT

HTTP://DX.DOI.ORG/10.5902/2316882X22921 


\section{CONSTRUÇÃO E COMUNICAÇÃO DE UMA MARCA TERRITORIAL: O CASO DO MUNICÍPIO DE VIANA DO CASTELO}

Resumo: Este trabalho está centrado no conceito de marca, de um modo geral, e no de place brand, em particular. Pretende-se, com este artigo, compreender de que modo a administração usa um conceito nascido em contexto empresarial para construir e posicionar uma marca municipal, local ou regional, e quais as implicações desta opção, na acção comunicativa, de natureza pública, dessa administração local. Para tal, analisaremos o caso especifico do município da cidade de Viana do Castelo, no Norte de Portugal.

Palavras-chave: marca; posicionamento; comunicação pública

\section{LA CONSTRUCCIÓN Y LA COMUNICACIÓN DE LA MARCA TERRITO- RIAL: EL CASO DEL AYUNTAMIENTO DE VIANA DO CASTELO}

Resumen: Este trabajo tiene como enfoque el concepto de marca en general y no de place brand en particular. El objetivo es entender cómo el poder municipal, através de un ayuntamiento, utiliza un concepto nacido en contexto empresarial para construir y posicionar una marca local y cuáles son las implicaciones de esta opción, en la acción comunicativa, de carácter público, de este ayuntamiento. Con esta finalidad, se analizará el caso específico de la ciudad de Viana do Castelo, Norte de Portugal. Palabras-clave: marca; posicionamento; e comunicacion pública

\section{CONSTRUCTION AND COMMUNICATION OF A TERRITORIAL BRAND: THE CASE OF VIANA DO CASTELO CITY}

Abstract: This paper focuses on the concept of brand, place brand specifically. The intention with this article is to understand how a local administration uses a born concept in business environment, as brand, to build and positioning a local brand and what are the implications of this option in the communicative action of this administration. To this end, we analyse the specific case of the city of Viana do Castelo, in north of Portugal. Keywords: brand; positioning; public communication 


\section{Introdução}

A importância da marca como "capital da empresa" tornou-a num fenómeno mundial que atravessa o planeta do Oriente a Ocidente, nos últimos 20 anos (COSTA, 2013). Essa importância que o conceito de marca adquiriu, num contexto altamente globalizado, é de tal ordem que, hoje, a marca não é um instrumento exclusivo dos fabricantes de produtos, mas também de fundações, governos, administrações regionais e locais, sindicatos, partidos políticos, indústrias culturais, e, até, países, territórios e cidades "querem ser marcas" (COSTA, 2013, p. 11).

A análise que procuramos realizar neste trabalho visa ir ao encontro desse salto do conceito da marca do sector empresarial para o sector público. Pretendemos compreender de que modo uma autarquia utiliza o conceito de marca como um "capital estratégico", no que respeita à construção de uma marca, sobre um território ou uma cidade, com o objectivo de alcançar um posicionamento que lhe dê vantagem competitiva, em termos de imagem.

Esta opção estratégica coloca, também, questões interessantes do ponto de vista da comunicação dessas organizações públicas. A acção comunicativa de uma autarquia é, tradicionalmente, colocada e analisada no âmbito do que chamamos comunicação pública. Na comunicação pública, pretende-se que o foco seja de interesse público no sentido em que a sua actuação procura contribuir para uma sociedade cidadã e democrática, com uma matriz informativa, elucidativa. A comunicação da marca, para além de informar, assume uma matriz mais imperativa e lúdica na perspectiva da persuasão. Sabemos que estas duas vertentes não se auto-excluem, mas como se articularam estas duas perspectivas no âmbito da comunicação de uma autarquia?

Assim, os objectivos deste trabalho podem ser agrupados em três eixos de orientação: a) identificar quais os elementos escolhidos pelo poder local para construir essa nova marca; b) identificar qual o posicionamento pretendido com essa nova marca para a cidade; c) compreender quais as opções desta aposta, - place brand - nas estratégias comunicacionais de um município.

De acordo com a definição destes eixos de orientação, começaremos por problematizar as temáticas intrínsecas a este estudo: o conceito de marca, o conceito de posicionamento e o de comunicação pública, muni- 
CADERNOS DE COMUNICAÇÃO

UNIVERSIDADE FEDERAL DE SANTA MARIA

cipal e de marca.

Na parte empírica do trabalho, começamos com uma pequena contextualização do "território" Viana do Castelo estudado, descreveremos o tipo de metodologia adoptado e justificamos a opção por estudo de caso. Passamos a análise detalhada do caso e terminamos este trabalho, com as considerações gerais onde procuramos responder aos objectivos definidos inicialmente.

\section{A marca}

Tradicionalmente, o conceito de marca tem sido enquadrado pelo marketing, desde que, na década de 60, a Associação de Marketing Americana, a definiu como um nome, um símbolo, um desenho, ou qualquer combinação entre estes elementos, com a finalidade de identificar bens ou serviços de um produtor. No entanto, nos últimos vinte anos, a conceptualização proveniente das várias áreas científicas tem sido prolífera em problematizar e discutir uma definição de marca bem mais complexa do que a dada pela Associação Americana de Marketing na década de 1960.

Desde a década de 1990 que a marca vem sendo descrita como uma proposta de "contrato" entre uma organização e o consumidor (KAPFERER, 1992), como uma forma de criar "vínculos" entre as empresas e o mercado (SCHULTZ; BARNES, 2001), como uma "promessa" entre uma empresa e os seus stakeholders (KELLER; MACHADO, 2006). É descrita como um "capital de uma empresa" com potencial activo e preventivo face aos riscos que as empresas enfrentam nos contextos onde actuam (COSTA, 2013). É neste contexto que a academia e as múltiplas profissões ligadas ao marketing e à comunicação debatem questões como a integridade da marca (KOTLER; KARTAJAYA; SETIWAN, 2015), a estrutura da marca (COSTA, 2013), a personalidade da marca (KAPFERER, 2003), a identidade da marca (GHODESWAR, 2008), a voz da marca (FONTVILA, 2013) e o rosto da marca (CULLERRÉ, 2013). A marca deixou há muito de ser apenas um símbolo e tornou-se fundamentalmente num discurso que pretende ser um elemento aglutinador de muitas dimensões, tanto reais como intangíveis. Esta perspectiva discursiva da marca poderá ajudar a explicar o sucesso do conceito de marcas fora dos contextos empresariais. Neste âmbito, as autarquias olham para as marcas não só como uma opção estratégica para promover os territórios e as cidades que administram, mas também como

Rev.Cad.Comun. Santa Maria, v.20, n.3, art 2, p.36 de 57, set/dez.2016 
uma possibilidade de potenciar a sua acção discursiva tanto do ponto de vista administrativo como político.

\section{Os "lugares" como marca}

Os lugares são o resultado dos diferentes discursos, que vão sendo criados e modificados ao longo do tempo por diferentes intervenientes. Esse processo de (re)construção é dinâmico pois a linguagem como prática social, ou seja, o discurso, forma a sociedade e vice-versa numa constante dialéctica onde a cultura é inerente (FAIRCLOUGH, 1989, 2006). Podemos, pois, afirmar que as identidades, as acções e as relações sociais são construídas a partir do discurso. Govers e Go (2009, p. 15) explanam de modo geral essa ideia explicitando que um lugar é um discurso - uma forma de construção de significado - o que influencia e organiza tanto as acções dos visitantes como as concepções dos residentes. De acordo com os autores, os significados estão contidos nas histórias que são contadas sobre o lugar, nas memórias, que conectam o seu presente com seu passado e nas imagens que são construídas a partir do lugar.

A produção de significados é, assim, interdependente do contexto da sua realização e dos participantes discursivos. Seguindo este entendimento, o estudo do que uma autarquia faz para a construção de uma marca territorial não pode ignorar determinados aspectos como o da cultura, na aceção STUART HALL (1997) que a descreve um "conjunto de significados partilhados". Conforme descrevem Silvestre e Marques (2014) estes significados são dinâmicos na mediada em que:

\footnotetext{
“os valores, as atitudes, os símbolos, (... ) as convenções, as narrativas, as histórias, os rituais, as práticas do dia-a-dia, a interação pessoal e social se intersetam em aspetos da cultura, que interligados, interagem na construção e transmissão de significados sociais. Nessas trocas culturais, percebemos uma cada vez maior necessidade com o elemento identitário, como forma de agregar valor ao grupo, quer este seja constituído por pessoas inscritas sob a denominação de país, região, cidade, instituição ou empresa. Os espaços geográficos ou territórios são, por conseguinte, convertidos em bens e serviços culturais, e têm hoje um peso económico cada vez mais importante, tornando-se produtos de exportação, comportando-se como verdadeiras marcas, seguindo lógicas de mercado.
} 
Tal explica a motivação do desenvolvimento de trabalhos no domínio das marcas territoriais. Não sendo aqui objecto de estudo as muitas designações que proliferaram, optámos por seguir a definição de Blain et al (2005, pp. 331-332): actividades de marketing que (i) apoiam a criação de um nome, símbolo, logo, marca nominativa ou gráfica que identificam e diferenciam um destino; (ii) transmitem a promessa de uma experiência de viagem memorável que está associada exclusivamente ao destino e (iii) servem para consolidar e reforçar a lembrança de memórias agradáveis da experiência do destino, tudo com o propósito de criar uma imagem que influencie as decisões do consumidor para visitar o destino em causa em oposição a outro alternativo.

Trata-se, pois, da representação de identidade, pela construção de uma imagem interna e externa favorável, ou melhor, da relação entre a identidade do lugar com imagens projectadas e percebidas através da comunicação e da experiência (GOVERS; GO, 2009). Essa construção é feita pelos intervenientes governamentais (ao nível nacional, regional ou local) que, em colaboração com parceiros do sector privado, criam a estratégia de branding. Cabe-Ihes avaliar (identificar as suas vantagens competitivas), (re)fazer, (re)posicionar, e (re)formular a identidade do lugar, a sua oferta de produto e, bem assim, as suas estratégias de comunicação. Estes elementos - identidade, oferta e imagem projectada - estão ligados de forma dinâmica. A âncora é a identidade do lugar onde se integram aspectos como a autencidade, a história, o meio envolvente e a cultura e que se inter-relaciona com a oferta do produto direccionado, nomeadamente, ao turismo, ao comércio, à fixação de população ou ao investimento. Esta mesma identidade conjuga-se com a imagem projetacda (dinamizada pela comunicação e significados criados pelas narrativas transmitidas e pelo visual) e vice-versa.

Neste universo dinâmico, a construção de identidades não é pacífica no sentido em que são construídas politicamente, podendo ser contestadas, o que também pode acontecer relativamente à autenticidade da marca. Esta última é frequentemente contestada porque, para além da autenticidade objectiva (já existente), se procede uma nova construção. Kotler Kartajaya e Setiwan (2015) apresentam um modelo de análise que poderá a ajudar a ultrapassar a contestação que o exercício de construção de identidade de uma marca pode originar. Para estes autores, a questão da autenticidade da marca pode ser resolvida através de um "triângulo

Rev.Cad.Comun. Santa Maria, v.20, n.3, art 2, p.38 de 57, set/dez.2016 
harmonioso" de marca, posicionamento e diferenciação. O triângulo proposto integra "três I's: a identidade da marca, a integridade da marca e a imagem da marca.

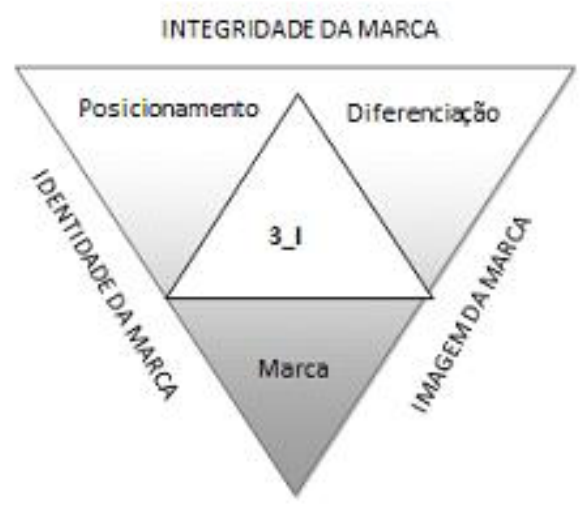

Figura 1 - Modelo dos três I.

Fonte: Kotler, Kartajaya e Setiwan (2015).

Para além de falarem de identidade e posicionamento, entendem necessário falar de diferenciação e defendem o seguinte:

A diferenciação é o 'ADN' da marca, que reflecte a sua integridade. É uma prova significativa de que uma marca está a fornecer aquilo que prometeu. (... ). Deste modo, a diferenciação estabelece uma sinergia com o posicionamento e irá automaticamente criar uma boa imagem de marca" (Kotler, Kartajaya e Setiwan, 2015, p. 49).

Assim, esta articulação diminui os riscos de uma marca ser questionada quanto à autenticidade da sua identidade. O modelo apresentado descreve que a identidade corresponde ao posicionamento da sua marca na mente dos consumidores (imagem pretendida). Este posicionamento tem, necessariamente, de ser único, para ser capaz de ser notado, num contexto sobrelotado de marcas. Ou seja, a integridade da marca corresponde à seriedade do que é prometido através do posicionamento e diferenciação (KOTLER, KARTAJAYA \& SETIWAN, 2015). Se os argumentos dados através deste triângulo forem credíveis, garantindo o cumprimento de uma promessa feita pela marca, esta acabará por merecer a confiança dos consumidores, isto é, a identidade da marca será percepcionada como autêntica e não será questionada. 


\section{Comunicar para construir e dar sentido à marca}

A comunicação de marca assume a função de transformar a identidade da marca em imagem da marca. Assim, a marca só existe porque é comunicada. No entanto, apesar de tal significar que a comunicação da marca se deve basear na identidade, não se pode ignorar que a comunicação é, também, parte integrante da própria identidade de uma marca (RUÃO, 2006; RUÃO; FARHANGMER, 2000). No processo de construção e comunicação de uma marca, a comunicação não pode ser encarada apenas como um veículo de expressão da realidade cultural que a marca incorpora. A comunicação é também uma constituinte da marca, na medida que pela comunicação ela se estrutura, se molda e se comporta, isto é, adquire sentido e se legitima e, assim, se torna tangível e relevante para as pessoas (FIGUEIRA, 2014). Esta perspectiva vai ao encontro do defendido no âmbito das teorias organizacionais que descrevem as organizações, e marcas, como "edifícios" que procuram adquirir sentido através da comunicação - sensemaking - (WEIK, 1995). A marca como discurso sobre uma cultura que procura integrar e dar voz é particularmente pertinente porque, na verdade, as pessoas não escolhem marcas, mas sim mitos, "estórias" e arquétipos que as marcam simbolizam (RODRIGUEZ, 2010).

Habitualmente, a comunicação da marca é enquadrada no conceito mais amplo de Comunicação Integrada de Marketing (CIM). A comunicação integrada de marketing envolve todas as formas de comunicação que suportam as vendas dos produtos, serviços e marcas (VAN RIEL; FOMBRUN, 2008; KUNSCH, 2003).) Para Kapferer (1994), o objectivo da comunicação no contexto da marca é expressar o conceito e a identidade da mesma e injectar valor conferindo-lhe significado e revestindo-a de simbolismo, daí a necessidade de se recorrer a uma linguagem simbólica, metafórica e idealizada. Hoje, a comunicação integrada de marketing, coloca ao serviço da construção de uma marca uma enorme panóplia de formas de comunicação, quer das tradicionais como a publicidade, relações públicas, publicity e eventos, às mais actuais como o ensorsement, o brand journalism ou contet marketing e as, redes sociais (SOBREIRA; ARRISCADO, 2015; RIES; RIES, 2008).

Rev.Cad.Comun. Santa Maria, v.20, n.3, art 2, p.40 de 57, set/dez.2016 


\section{A comunicação de uma marca no contexto da comunica- ção pública.}

Considerando a natureza e o escopo deste estudo, interessa focar a atenção no facto de a marca ser construída na base da comunicação pública, ou seja, num processo de comunicação instaurado entre Estado, Governo, Organizações, Agentes Sociais, Pessoas e Sociedade Civil (BRANDÃO, 2015).

Quando falamos de comunicação pública, tem implícitas duas esferas de actuação, uma esfera governativa, quando falamos da acção comunicativa entre poderes executivos e a sociedade, e uma esfera pública, quando estamos perante a acção como comunicativa da sociedade civil no âmbito do exercício de cidadania. No contexto deste trabalho, interessa-nos sobretudo a primeira, a esfera governativa, por enquadrarmos nesse domínio a actuação de uma autarquia.

Camilo (1998, p. 15) descreve a comunicação municipal como "um conjunto global, coerente e contínuo de acções comunicacionais concretizadas pela estrutura institucional de um município, a Câmara Municipal, a Assembleia Municipal ou o Presidente da Câmara”. Para Camilo (1998), a comunicação municipal pode actualmente ser agrupada em três vertentes: Informacional, Política e Simbólica. Resumidamente, a vertente informacional, mais próxima da perspectiva tradicional, diz respeito à publicitação (no sentido da difusão pública) e que até está abrangida pela lei, sobre as decisões dos órgãos municipais. A vertente política tem por objectivo a legitimação das decisões e dos actos políticos subjacentes às escolhas administrativas ou decisões dos autarcas. Por fim, a comunicação simbólica é aquela que procura dinamizar uma "certa identidade sócio-cultural local", para além das fronteiras físicas e jurídicas do município. E, nesta medida, ao comunicar as peculiaridades das identidades locais, procura diferenciar os municípios ou comunidades vizinhas entre si (CAMILO, 1998). Para o autor, esta vertente tem uma dimensão comunicacional corporativa e é, portanto, nesta vertente que a comunicação de uma marca municipal deve ser enquadrada.

\section{Estudo de Caso: A marca Viana do Castelo}

Viana do Castelo é um município situado no Litoral Norte de Portugal que integra actualmente a sub-região do Minho-Lima. Localizado na foz 
do rio Lima e, no sopé do Monte de Santa Luzia, situa-se a cerca de 70 quilómetros do Porto, a segunda maior cidade do país.

Pela sua localização, Viana do Castelo sempre esteve historicamente muito ligada ao mar. Durante todo o século XX, os Estaleiros Navais da cidade foram uma referência da construção naval.

Nos dias de hoje, a economia de Viana do Castelo já não se sustenta nos seus Estaleiros Navais, como outrora, mas no turismo, no comércio e nos serviços. Porém, a cidade continua ligada ao mar, combinando uma localização privilegiada de mar, rio e montanha com um património monumental, de onde se destaca o Centro Histórico, assim como uma oferta de eventos relacionada com a sua cultura popular, a etnografia e o artesanato local, onde são valorizados os trajes femininos ricamente decorados, os bordados típicos e a ourivesaria fortemente marcada pela técnica da filigrana que tornaram Viana do Castelo numa montra e num ex-libris dessa tradição de ourivesaria.

\section{Metodologia}

Tendo em conta a aplicabilidade a contextos da vida real, optámos por um estudo de caso, a marca de um município português. $O$ estudo de caso apresentado enquadra-se, de acordo com Yin (2003), no tipo descritivo único, uma vez que tem por base a análise de um único caso.

Para analisarmos o nosso caso e de modo a conseguir a profundidade desejada, recorremos a uma abordagem transdisciplinar, no sentido em que o diálogo entre diferentes disciplinas e teorias possibilitam o desenvolvimento desta pesquisa. Assim, baseámos a revisão da literatura em princípios da comunicação, do marketing e branding e da linguística aplicada. De seguida, procedemos à análise do Relatório de Plano de Marketing para Viana do Castelo: num primeiro momento, realizámos uma análise quantitativa, com a ajuda do programa informático Wordsmith Tools (versão 4). O programa foi utilizado pelo recurso à Lista de Palavras por ordem de frequência (Wordlist) e à Co-ocorrência de palavras (Concord). A análise qualitativa teve como base uma análise documental, o que permitiu a construção de uma matriz identitária, em resposta ao triângulo de Kotler, Kartajaya e Setiwan (2015). 


\section{Análise da marca Viana}

A marca Viana, solicitada pela Câmara Municipal de Viana do Castelo, foi concebida pela agência de design Ativism e lançada em agosto de 2010. Para este estudo, analisámos o Relatório final do plano de marketing para Viana do Castelo, entregue a 14 de junho de 2011.

Num primeiro momento, observámos quais as palavras mais utilizadas no relatório, tendo por base o entendimento de que os falantes de uma língua realizam escolhas léxico-gramaticais de entre um potencial de escolhas (HALLIDAY, 1978, p. 52). Procedemos, então, ao levantamento das palavras com conteúdo conceptual mais utilizadas, excluindo as palavras que têm apenas uma função gramatical. A partir daí, identificámos que a palavra mais escolhida foi "território" (84 ocorrências) e a segunda foi "cidade" (58 ocorrências). Estes dados indicam que a opção do município para construir uma nova marca territorial se enquadra no âmbito deste trabalho, ou seja, o marketing territorial e, especificamente, que é a partir das associações a esse território que se pretende construir a nova marca.

De seguida, analisámos o Relatório incidindo a nossa análise no ponto 3 ("Estratégia de Marketing para Viana do Castelo"), onde são abordadas as temáticas de dimensão estratégica abordadas: diagnóstico da situação (p. 23), diferenciação e posicionamento pretendido (p. 25) para a nova marca (pp. 26-28) e comunicação (p. 43).

A vantagem competitiva apresentada baseia-se em algo intangível: a tradição. E a história que se pretende contar é a de Viana cidade dos namorados. Interessa, pois, perceber como é contada e através de que elementos.

No Relatório, Viana é projectada (posicionamento) como a "cidade do amor" para os seguintes públicos-alvo: residentes, turistas e investidores (p. 24). E, para cada um destes, a autarquia cria uma "categoria" que fale ao coração de cada um deles. Para os primeiros, trata-se de uma cidade para os amantes de cidades, uma cidade feita à escala das pessoas, dos "city lovers". Para os segundos - os turistas - pretende-se um destino emocional e afetivo, simbólico do amor, a "cidade dos namorados". Para os investidores, é a cidade dos "work lovers".

Esta ideia de cidade dos namorados está, de acordo com o Relatório (p. 26), ancorada no património da cidade e do território e reflecte a essência de Viana: "A nova marca traduz o que de mais profundo caracteriza 
Viana e mostra aquilo que de mais perene o território tem para oferecer: uma cultura de amor e de serviço, de desafio e de ousadia, de serenidade e de tradição, de alegria e felicidade". Para representar graficamente este espírito, recorreu-se a uma das mais icónicas jóias que as vianenses usam como adorno: o coração de ouro em filigrana (ver figuras 2 e 3). Podemos afirmar que este é um dos elementos centrais de identidade que passa a ser reproduzido para o desenvolvimento da marca Viana.

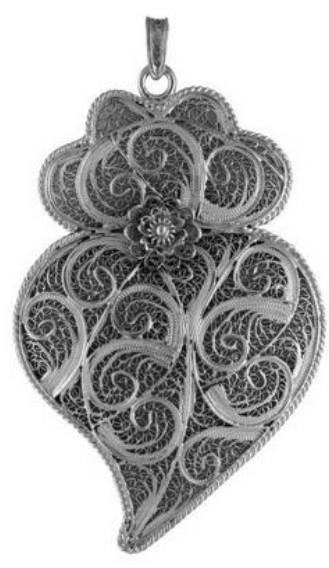

Figura 2 - Coração de Viana.

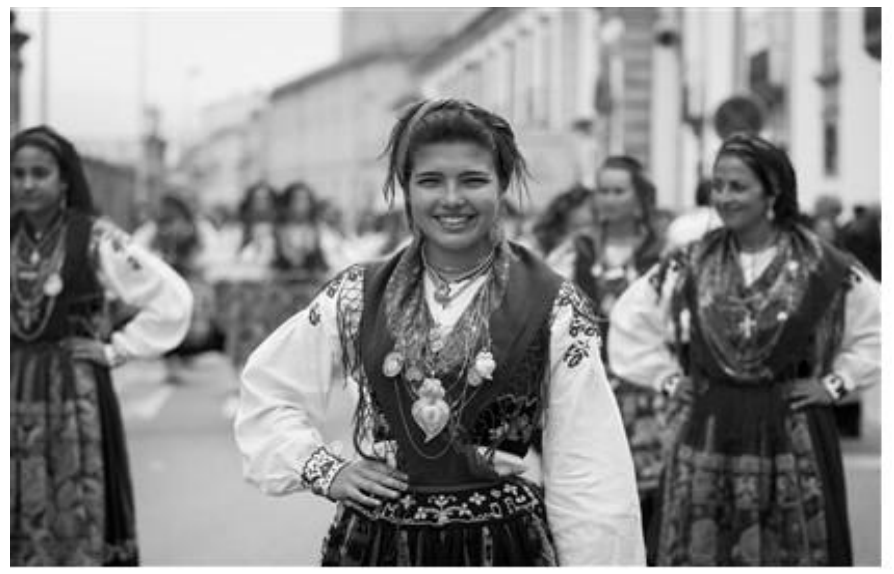

Figura 3 - Mordoma usando um coração de Viana.

O Relatório refere que o coração, hoje símbolo da cidade do amor, tem a sua raíz no culto ao Sagrado Coração de Jesus, venerado na Igreja no alto do Monte de Santa Luzia, que, no mês de julho, junta milhares de vianenses. No entanto, apesar desta génese de matriz religiosa, esta peça de ourivesaria adquiriu há muito um simbolismo que vai além do religioso, também resultado da sua apropriação por parte da artista plástica Joana Vasconcelos e a criação do seu gigantesco "Coração Independente" de cor vermelha', que lhe deu projecção nacional e internacional.

Resumindo, do ponto de vista da integridade da marca (KOTLER; KARTAJAYA; SETIWAN, 2015), a marca Viana procura posicionar-se como uma cidade bonita, vibrante que cultiva o amor. A marca sustenta esse posicionamento de forma sólida, em nosso entender, na medida em que a cidade é amplamente conhecida pelo seu património arquitectónico, mas sobretudo o simbólico associado ao amor, como "a cidade dos namorados", "o

1 O coração em exposição no Palácio Nacional da Ajuda (Lisboa), de 23 de Março a 25 de Agosto de 2013. A explicação do objeto e fotos estão disponíveis em http://www. joanavasconcelos-pnajuda.pt/exposicao/coracao-independente-vermelho-2005.

Rev.Cad.Comun. Santa Maria, v.20, n.3, art 2, p.44 de 57, set/dez.2016 
trajes típicos de mordoma e noiva de Viana", as alegres festas religiosas, o coração de filigrana e a cor vermelha preponderante nos trajes típicos que as vianenses usam nas romarias que se organizam no Minho.

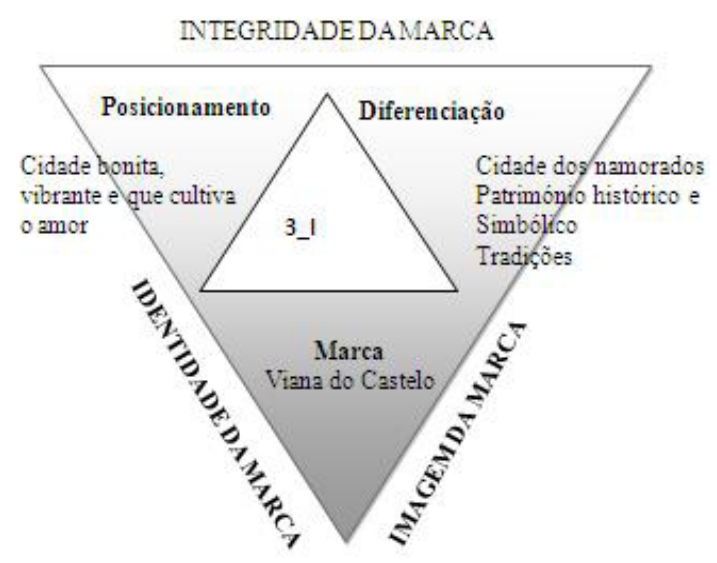

Figura 4 - Modelo dos três I construído para a marca Viana.

Fonte: Modelo adaptado a partir de Kotler, Kartajaya e Setiwan (2015).

Esta matriz identitária foi materializada nos seguintes elementos: um logotipo e uma assinatura. O logótipo, que se pode observar abaixo, salienta-se, no topo, a representação das chamas que, no original, estão na cornucópia inicial do coração:

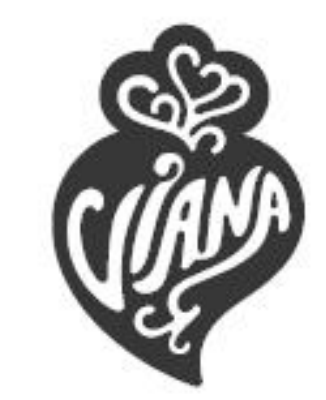

FICA NO CORAÇĂO

Figura 5 - Novo logótipo.

Fonte: Kit de Normas básicas de identidade da marca Viana (2010).

O logótipo em questão surge com coração em vermelho e o fundo branco, podendo, no entanto apresentar outras opções que alternam entre o vermelho e o preto, cores importantes na identidade de Viana. Pode surgir também em fundos com intensidades diferentes/fotográficos e, em casos especiais e internamente para uso específico da Câmara Municipal, em cor dourada.

Rev.Cad.Comun. Santa Maria, v.20, n.3, art 2, p.45 de 57, set/dez.2016 
A assinatura: "Fica no coração" que lida com a palavra que surge no centro do logotipo, complementa: Viana, Fica Coração. Esta assinatura surge por vezes desdobrada na forma: "Quem gosta vem, quem ama fica".

\section{Comunicação da nova marca}

As linhas estratégicas apresentadas pela empresa responsável apontam para a necessidade de "sensibilizar os diversos parceiros e agentes do território para que a umbrella da marca funcione" (ATIVISM, 2011, p. 43.). Os autores do projecto afirmam que a comunicação é fundamental para que a marca seja mais do que um símbolo: "não basta usar um símbolo, é preciso que todos se unam em torno do discurso e dos valores da marca e dos respectivos posicionamentos" (p. 43).

As sugestões apontadas pelos especialistas da Ativism passaram tanto por novas ideias e acções, como pelo potenciar de iniciativas já organizadas pela autarquia. O plano de sensibilização para a nova marca sugeria acções de: "recrutamento" de parceiros estratégicos autárquicos e regionais, roadshow pelas festas e romarias do concelho, o rebaptizar de eventos já existentes, como a Maratona Manuela Machado e a Bienal e, por fim, a organização de um colóquio dedicado à temática marketing territoriais e o papel das marcas nos territórios (p. 44).

As evidências encontradas apontam para:

a) a realização de eventos, como um logotipo humano composto por mordomas, lavradeiras e noivas com os trajes típicos de Viana:

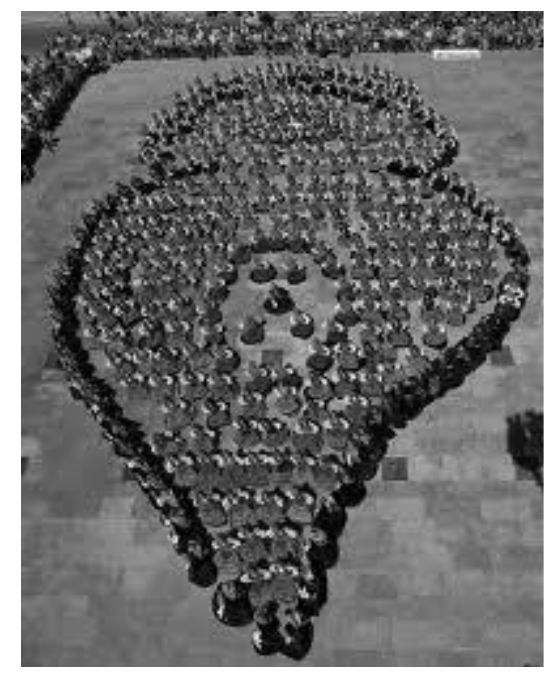

Figura 6 - Composição em forma de coração.

Fonte: Simecq.Cultura (2009).

Rev.Cad.Comun. Santa Maria, v.20, n.3, art 2, p.46 de 57, set/dez.2016 
b) associação a figuras públicas (endorsement) à nova marca. A 2 de Agosto de 2010, decorreu o concerto “Viana no Coração", com uma conhecida fadista portuguesa, Kátia Guerreiro que inaugura uma parceria entre a autarquia e a artista:

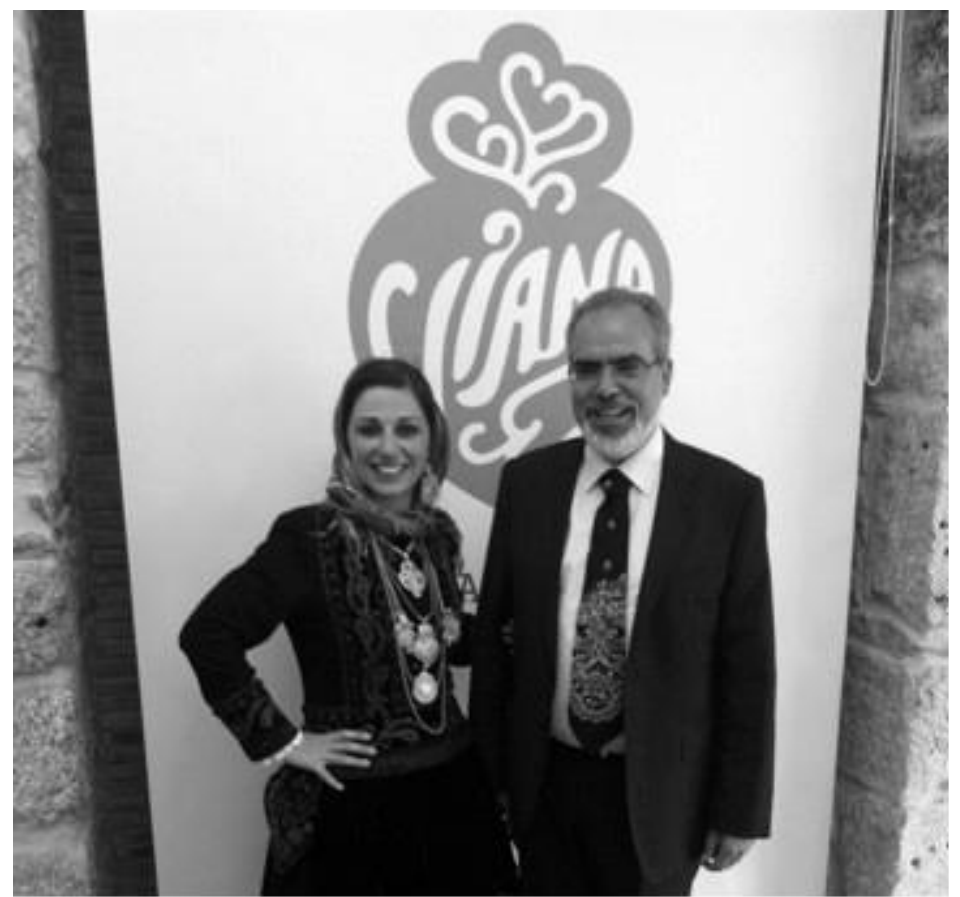

Figura 7 - Kátia Guerreiro e o Presidente da Câmara.

Fonte: Blogue da fadista (http://katiaguerreiro_pt.blogs.sapo.pt/32946.html).

A fadista aparece, mais tarde, descrita pela comunicação social local (CORREIO DO MINHO, 2011), como sendo embaixadora da nova marca de Viana: “A iniciativa, apresentada em Viana do Castelo, faz parte da parceria estabelecida entre o município e Kátia Guerreiro, nomeada 'embaixadora' da nova marca da cidade, que foi lançada em agosto de 2010." (CORREIO DO MINHO, 2011).

c) comunicação social foi também usada para dar voz à nova marca (publicity). Segundo a assessoria de imprensa da autarquia, "na altura foi efetuada uma apresentação para a comunicação social”. É possível encontrar notícias tanto na imprensa nacional (ex: ver figura 8), como na imprensa especializada (revista Marketeer de 02 de Agosto de 2010): 


\section{Jomalde Noticias}

Viana do Castelo

\section{Amor inspira nova imagem do municipio altominhoto}

\begin{abstract}
Ana Peixoto Fernandes

03. Agosto 2010 às $00: 30$

Um coração, a lembrar os típicos de filigrana, foi ontem apresentado como a nova marca do município de Viana do Castelo, que hoje invadirá as ruas e de que a fadista Kátia Guerreiro é um dos rostos da campanha.
\end{abstract}

Figura 8 - Notícia sobre a apresentação da marca.

Fonte: Jornal de Notícias de 02 de Agosto de 2010.

d) as redes sociais foram igualmente usadas; neste caso, foi lançada uma página do Facebook:

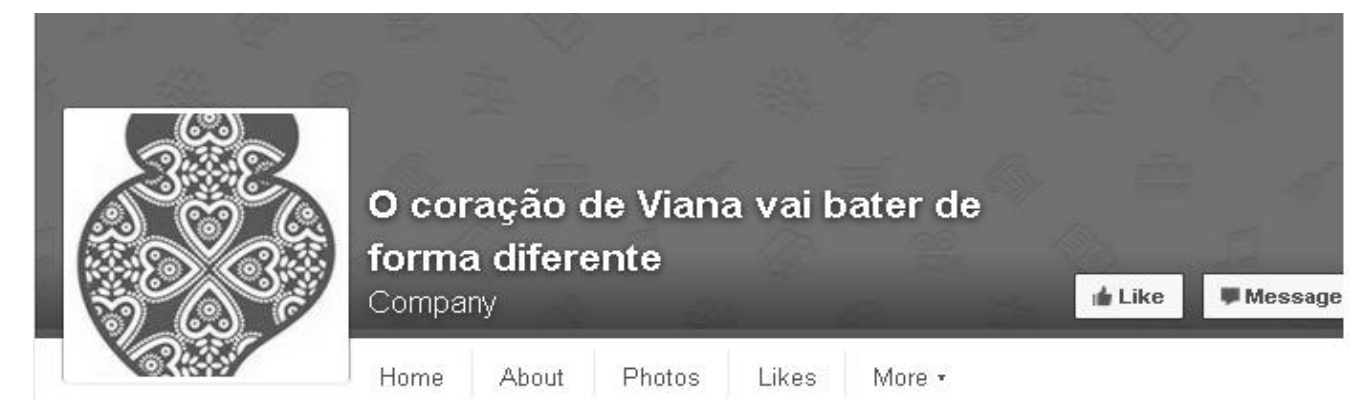

Figura 9 - Página de Facebook criada pela Câmara. Fonte: Facebook.

e) a meia maratona Manuela Machado, não mudou de mome, mas o discurso da marca foi definitivamente incorporado neste evento. 


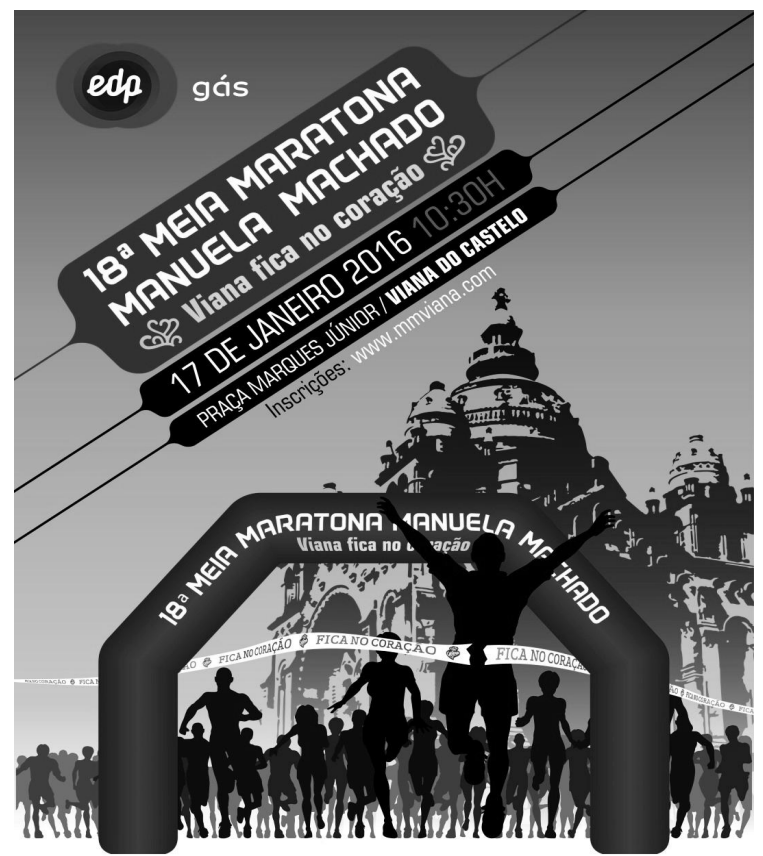

Figura 10 - Cartaz alusivo à $18^{\mathrm{a}}$ Meia Maratona Manuela Machado (2016).

Fonte: Website da Câmara Municipal de Viana do Castelo.

f) a criação de "brindes" (merchandising), com a adaptação do coração apara ser usado como um leque, e distribuído durante as festas da cidade, com a frase "com o coração nas mãos" no verso:

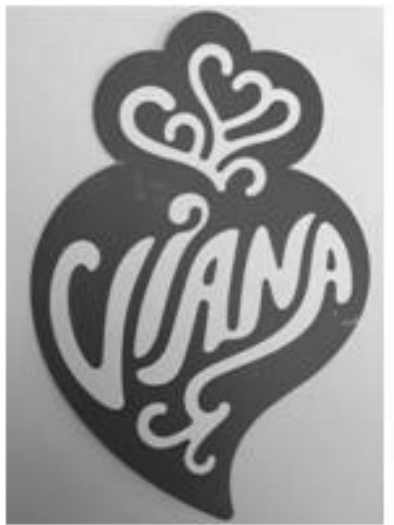

(Frente)

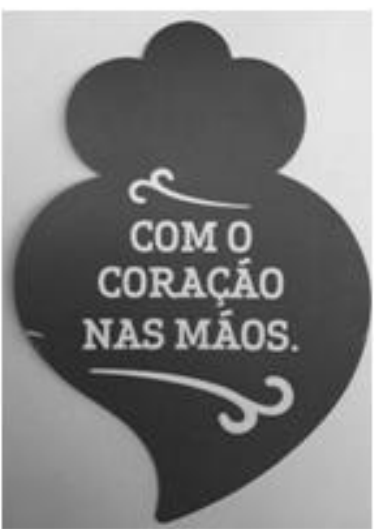

(Verso)

rıgura 11 - coraçao adaptado a Ieque.

Do ponto de vista da comunicação, para além da forma como o município comunicou esta mudança identitária aos seus públicos, importa também analisar outra dimensão: como é que esta nova marca foi integrada do ponto de vista da identidade, nos moldes descritos por Silvestre e Marques (2014). E, neste aspecto, é interessante verificar como a autarquia se apro- 
priou desta nova simbologia e a integra na sua narrativa institucional.

Tendo em conta a diferenciação sobre as vertentes da comunicação municipal (política, administrativa, simbólica), poderíamos verificar uma diferenciação acentuada entre os três tipos. Ou seja, uma separação de águas entre acção administrativa e política da autarquia, mais sóbria, e a dimensão simbólica, mais lúdica ou metafórica. No entanto, o que verificamos aponta para uma integração completa entre essas diferentes vertentes da comunicação municipal. A situação mais emblemática diz respeito ao símbolo. $\mathrm{O}$ tradicional brasão construído nos moldes da heráldica tradicional (figura 12), que honra a tradição sócio-económica da região, foi substituído pelo novo logótipo (o coração de Viana).

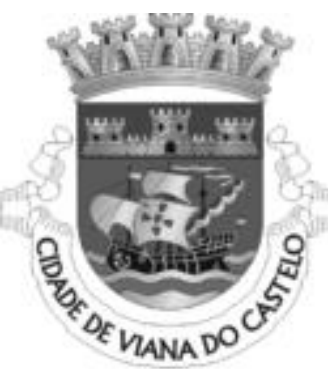

Figura 12 - Brasão de Viana do Castelo.

A título de exemplo, no sítio Web da Câmara Municipal, o coração passou a ser a única opção, como se pode observar na figura seguinte:

\section{C.\$ $16^{\circ}$ Vianado Castelo, PT .... RSSFeed Newsletter Mapado Site Contactos (30 Seleccionar idioma|}

MUNÍCIPE

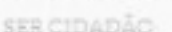

EMPREENDEDOR

EsPaco paRA EMRazsas

Figura 13 - Topo da primeira página Web da Câmara Municipal de Viana do Castelo.

Fonte: Website da Câmara Municipal de Viana do Castelo.

\section{Considerações finais}

A nova identidade visual tem claramente a intenção de modernizar a imagem do município. Esta aposta da autarquia vai ao encontro das tendências observáveis desde o início dos anos 2000, no sentido em que este 
tipo de organizações passou a adoptar um discurso visual mais próximo do conceito de marketing de território, em particular do de local brand, como forma de diferenciação face a outros territórios.

No início deste trabalho, propusemo-nos: identificar quais os elementos escolhidos pelo poder local para construir essa nova marca. Do ponto de vista da nova identidade, há um exercício de integração dos elementos do território e da sua cultura, nesta nova identidade, o que, por sua vez, reconfigura a existente numa perspectiva de modernidade. Por um lado, olhando para a marca criada, são evidentes os elementos usados do ponto de vista visual: a forma do coração, uma constante na ourivesaria e no artesanato local; os traços que remetem para o fio de filigrana ou o vermeIho, cor preponderante nos trajes e nos bordados de Viana do Castelo. Por outro lado, se o coração já fazia parte da identidade deste território, pela associação religiosa, com esta nova configuração ganha uma nova dimensão no sentido em que ultrapassa o simbolismo religioso, que possui neste espaço, para a uma dimensão afectiva: o símbolo do amor. Temos, assim, a construção de uma marca que aposta na promoção da sua identidade "única" como vantagem competitiva em relação a outros territórios.

O segundo objectivo era identificar qual o posicionamento pretendido com essa nova marca para a cidade. Sabemos que o posicionamento consiste numa declaração de como pretendemos que uma marca seja percepcionada, para obtermos uma imagem favorável. No caso analisado, pretende-se que a cidade de Viana do Castelo seja percepcionada como sendo sinónimo da "cultura do amor", para quem lá vive, para quem a visita e para quem lá trabalha ou deseja vir trabalhar. É a "promessa" que Keller e Machado (2006) referem. E os argumentos que sustentam esta promessa são, mais uma vez, escolhidos pelo que diferencia este território, ou seja, as suas tradições associadas ao romantismo, a "cidade dos namorados", o património histórico, a localização versátil de serra, rio e mar e as tradições folclóricas e etnográficas. Neste sentido, proporciona memórias e experiência agradáveis sobre destino, de acordo com o descrito Blain et al (2005). Desta forma, ao cumprir essa promessa, a marca procura criar "vínculos" como o defendido por Schultz e Barnes (2001). Este posicionamento de que Viana do Castelo é uma cidade do amor e que proporciona experiências memoráveis materializa-se também na assinatura/slogan idealizados que acompanha marca: "Viana Fica no Coração" e nos seus desdobramentos: "Quem gosta vem, quem ama fica" e "Com o 
CADERNOS DE COMUNICAÇÃO

UNIVERSIDADE FEDERAL DE SANTA MARIA

coração [de Viana] nas mãos".

Por fim, pretendia-se perceber quais as opções desta aposta, - place brand - nas estratégias comunicacionais de um município. A comunicação municipal enquadra-se no âmbito da comunicação pública, com objectivos informacionais sobre as acções administrativas e políticas, e que procura, de alguma forma, legitimar a acção dos agentes políticos. Mas, segundo Camilo (1998), a comunicação municipal tem um importante papel simbólico e referencial no sentido em que trabalha por e sobre a identidade de um determinado território. Nesta medida, as evidências que encontramos apontam para um intenso trabalho de sensibilização e aceitação da nova marca para a cidade por forma a diferenciar a cidade de forma significativa face aos outros territórios adjacentes. A estratégia de acção de comunicação aponta para o uso tanto de formas tradicionais de comunicação como das mais associadas à comunicação de marketing. O lançamento da nova marca recebeu atenção dos órgãos de comunicação social locais e nacionais, onde a empresa responsável pelo projecto assume o papel de porta-voz, o que parece confirmar a importância das estratégias informativas na comunicação de marca, como defendem Sobreira e Arriscado (2015); Ries e Ries, (2008). É possível, também, identificar formas mais “irreverentes" de chamar a atenção sobre a nova marca, como o logótipo humano e a presença da fadista Kátia Guerreiro como embaixadora da marca, que incorpora o conceito de tradição pelo estilo musical que promove, muito próximo do conceito de endorsement, usado nas estratégias de comunicação de marca. É como se, para além de uma imagem gráfica (logótipo) e de um lema (slogan), a nova marca também tivesse uma voz, a voz de Katia Guerreiro. A perspectiva tradicional da comunicação que procura informar, através de uma dimensão mais informacional, permite credibilizar e dar autenticidade à nova identidade da marca, de modo a que não seja questionada. A utilização de uma linguagem mais simbólica, metafórica e idealizada, presente no logo humano, no merchandising ("Com o coração nas mãos") e na escolha de uma embaixadora para a marca, aproxima a estratégia de comunicação adoptada na perspectiva de Kapferer (1994), que atribui à comunicação a responsabilidade de injectar na marca valor conferindo-lhe significado.

Por outro lado, não podemos ignorar que esta nova marca vem assumir um papel aglutinador e de integração da própria acção política da Câmara. A nova marca está, de facto, presente em todas as formas de comu-

Rev.Cad.Comun. Santa Maria, v.20, n.3, art 2, p.52 de 57, set/dez.2016 
nicação municipal: Informacional, Política e Simbólica. Do ponto de vista da acção política do município, todos os seus serviços passam a estar sob esta nova identidade, como é o caso do Museu do Traje, do Museu de Artes Decorativas e do Turismo de Viana do Castelo. Ou seja, de acordo com a análise realizada, defendemos que a nova marca serve também para unificar e dar coerência à acção administrativa e política do poder local.

\section{REFERÊNCIAS}

AAKER, D. Building Strong Brands, N. York: The Free Press, 1996.

AAKER, D. Managing Brand Equity. N. York: The Free Press, 1991.

Ativism assina marca Viana do Castelo. Marketeer, 02 de Agosto de 2010. Disponível em: http://marketeer.pt/2010/08/02/ativism-assina-marca-viana-do-castelo/.Acesso em: Novembro de 2015.

ATIVISM. Kit de Normas básicas de identidade da marca Viana, 2010.

ATIVISM. Relatório de Plano de Marketing para Viana do Castelo, 2011.

BLAIN, C.; LEVY, S. E.; RITCHIE, J. R. B. Destination Branding: Insights and Practices from Destination Management Organizations. Journal of Travel Research, Sage Publications, v. 43, p. 328-338, may 2005 .

BRANDÃO, E. P. Usos e Significados do Conceito Comunicação Pública. IN: ENCONTRO DOS NÚCLEOS DE PESQUISA DA INTERCOM, v. 6, 2006. Disponível em: http:// www.portcom.intercom.org.br/pdfs/38942022201012711408495905478367291786.pdf. Acesso em: Novembro de 2015.

C MARA MUNICIPAL DE VIANA DO CASTELO. Brochura Viana Fica no Coração. Disponível em: www.cm-viana-castelo.pt/.../33dfea3d563d2b730aof8d267160ao7b. Acesso em: Abril de 2016.

C MARA MUNICIPAL DE VIANA DO CASTELO. Meia Maratona Manuela Machado - Viana Fica no Coração. Disponível em: http://www.cm-viana-castelo.pt/pt/agenda-cultural/ meia-maratona-manuela-machado-viana-fica-no-coracao-2016. Acesso em: Abril de 2016.

C MARA MUNICIPAL DE VIANA DO CASTELO. Primeira Página do Website. Disponível em:http://www.cm-viana-castelo.pt. Acesso em: Abril de 2016.

CAMILO, E. Estratégias de Comunicação Municipal - Uma Reflexão sobre as Modalida-

Rev.Cad.Comun. Santa Maria, v.20, n.3, art 2, p.53 de 57, set/dez.2016 
CADERNOS DE COMUNICAÇÃO

UNIVERSIDADE FEDERAL DE SANTA MARIA

des de Comunicação nos Municípios, Covilhã: Universidade da Beira Interior, 1998.

COSTA, J. Los cinco pilares del branding: Anatomia de uma marca. Barcelona: CPC Editor, 2013.

CULLERÉ, A. El Rosto de la marca. In: COSTA, J. (ed.). Los Cinco Pilares del Branding: Anatomia de uma marca. CPC Barcelona, 2013.

DUARTE, J. Comunicação Pública. Disponível em http://www.jforni.jor.br/forni/files/ ComP\%C3\%BAblicaJDuartevf.pdf. Acesso em: Novembro de 2014.

FAIRCLOUGH, N. Language and Power, London: Longman, 1989.

FAIRCLOUGH, N. Language and Globalization, London: Routledge, 2006.

FERNANDES, A. P. Amor inspira nova imagem do município altominhoto. Jornal de Notícias, 03 de Agosto de 2010. Disponível em: http://www.jn.pt/local/noticias/viana-do-castelo/viana-do-castelo/interior/amor-inspira-nova-imagem-do-municipio-altominhoto-1632560.html. Acesso em Novembro de 2015.

FIGUEIRA, J. A Vida é Bela: Processos de Institucionalização e Construção de Sentido através dos Media. In RUÃO, T.; KUNSCH, M. (Ed.). Comunicação e Soçiedade - Tendências da Comunicação Organizacional e Estrategica, 6, 47-71, 2014, Universidade do Minho. Disponível em: https://repositorium.sdum.uminho.pt/bitstream/1822/33025/1/ Revista_26.pdf. Acesso em: Novembro de 2015.

GHODESWAR, B. Building Brand Identity in competitive markets: a conceptual framework, Journal of Product and Brand Management, 17(1), 4-12, 2008.

FACEBOOK. O coração de Viana vai bater de forma diferente. Disponível em: https:// www.facebook.com/148254395189434/photos/a.161893360492204.42740.148254. Acesso em Janeiro de 2016.

FONTVILA, I. La voz de lá marca. In: COSTA, J. (ed.). Los Cinco Pilares del Branding: Anatomia de uma marca. CPC Barcelona, 2013.

GHODESWAR, B. Building Brand Identity in competitive markets: a conceptual framework, Journal of Product and Brand Management, 17(1), 4-12, 2008.

KELLER, K. L. Conceptualizing, Measuring, and Managing Customer-Based Brand Equity, Journal of Marketing, 57, 1-22, 1993.

GOVERS, R.; GO, F. Place Branding - Glocal, Virtual and Physical Identities, Constructed, Imagined and Experienced, U.K.: Palgrave Macmillan, 2009.

GUERREIRO, K. Festas da Senhora D’ Agonia em Viana do Castelo, 22 de Agosto de

Rev.Cad.Comun. Santa Maria, v.20, n.3, art 2, p.54 de 57, set/dez.2016 
2011. Disponível em: http://katiaguerreiro_pt.blogs.sapo.pt/32946.html. Acesso em: Dezembro de 20015.

HALLIDAY, , M. A. K. (1978). Language as social semiotic: The social interpretation of language and meaning, London: Edward Arnold, 1978.

KAPFERER, J.N. As Marcas, Capital da Empresa: Criar e desenvolver marcas fortes, Porto Alegre: Bookman, 2003.

KAPFERER, J.N. Marcas: Capital da Empresa, Lisboa: Edições CETOP, 1994.

KAPFERER, J.N. Strategic Brand Management, new approaches to creating and evaluating brand equity, N. York: The Free Press, 1992.

KELLER, K. L. Conceptualizing, Measuring, and Managing Customer-Based Brand Equity, Journal of Marketing, 57, 1-22, 1993.

KELLER, K. L.; MACHADO, M. Gestão estratégica de marcas, São Paulo: Pearson Prentice Hall, 2006.

KOTLER, P. H; KARTAJAYA, H; SETIWAN, I. Marketing 3.0: Do Produto e do Consumo até ao Espírito Humano, Lisboa: Actual Editora, 2015.

KUNSCH, M. K. Planejamento de Relações Públicas na Comunicação Integrada. $4^{\text {a }}$ edição. São Paulo: Summus Editorial, 2003.

Milhares na rua para ver mordomas carregadas de ouro. Diário de Notícias, Portugal, 16 de Agosto de 2013. Disponível em: http://www.dn.pt/portugal/norte/interior/milhares-na-rua-para-ver-mordomas-carregadas-de-ouro-3374389.html. Acesso em Novembro de 2015.

RIES A.; RIES L. A Queda da Publicidade e a Ascensão das Relações Públicas. Lisboa: Casa das Letras, 2008

RODRIGUEZ, M. T. Storytelling. La maquina de Fabricar histórias e Formatear las Mentes. Revista Comunicación, 8(1) , 89-93, 2010.

RUÃO, T. Marcas e Identidades: Guia da concepção e gestão das marcas comerciais, Porto: Campo das Letras, 2006.

RUÃO, T.; FARHANGMER, M. A imagem de marca: análise das funções de representação e apelo no marketing das marcas. Um estudo de caso. Actas do I Seminário de Marketing Estratégico e Planeamento, Escola de Economia e Gestão, Universidade do Minho, 1-11, 2000.

SILVESTRE,C; MARQUES, G. A Construção Semiótico Discursiva da Marca 'Nazare’s

Rev.Cad.Comun. Santa Maria, v.20, n.3, art 2, p.55 de 57, set/dez.2016 
Great Canyon'. In: Lusocom - Marca territorio: a construción da(s) identidade(s) a través da communicación, XI, Universidad de Vigo, 2014. (no prelo).

SOBREIRA, R.M.; ARRISCADO, P. A importância da Assessoria Mediática na Activação da Marca: Análise de Caso de uma Marca do Sector Automóvel. Brand Trends: Journal of Strategic Communication and Branding, 4, 7(7) Outubro de 2014.

SCHULTZ, D. E.; BARNES, B. E. Campanhas Estratégicas de Comunicação de Marca. Rio de Janeiro: Qualitymark, 2001.

SIMECQ.CULTURA. Coração de Viana, 25 de Outubro de 2009. Disponível em: http:// simecqcultura.blogspot.pt/2009/10/coracao-de-viana.html. Acesso em: Dezembro de 2015.

VAN RIEL, C. B ; FOMBRUN, C. J. Essentials of Corporate Communication - Implementing Practices for Effective Reputation Management. London: Routledge, 2008.

VASCONCELOS, J. Exposição no Palácio Nacional da Ajuda, 2005. Disponível em: http:// www.joanavasconcelos-pnajuda.pt/exposicao/coracao-independente-vermelho-2005. Acesso em: Novembro de 2015.

Viana: Kátia Guerreiro e coração de Viana juntos na 'Caixa dos Amores'. Correio do Minho, Alto Minho, 14 de Fevereiro de 2011. Disponível em: http://www.correiodominho. com/noticias.php?id=43217. Acesso em Novembro de 2015.

WEIK, K. Sensemaking in organizations. Neubury Park. CA: Sage publications, 1995.

YIN, R. Case Study Research.3 ed. London: Sage, 2003. 


\section{Resumo sobre autores:}

Gorete Marques

Professora Adjunta no Instituto Politécnico de Leiria nas áreas de Gestão da Comunicação, Metodologia e Francês para fins específicos. É doutora em Linguística Aplicada pela Universidade de Lisboa e membro do centro de investigação CELGA-ILTEC.

\section{Rosa Sobreira}

Professora Adjunta no Instituto Politécnico de Coimbra, nas áreas de Comunicação Estratégica, Comunicação de Marketing e Assessoria de Imprensa. É doutorada em Comunicação Estratégica pela Universidade Nova de Lisboas e investigadora do CEIS_20 da Universidade de Coimbra.

RECEBIDO EM: 30/06/2016

ACEITO EM: 23/08/2016 